\title{
Synthesis of $\alpha$-L-Fucose-I- ${ }^{14} C$ (6-Deoxy-L-galactose-I- ${ }^{14} C$ )
}

\author{
H. S. Isbell, H. L. Frush, and N. B. Holt \\ Institute for Materials Research, National Bureau of Standards, Waśhington, D.C. 20234
}

(October 31, 1966)

\begin{abstract}
$\alpha$-L-Fucose- $1-{ }^{14} \mathrm{C}$ was synthesized in a radiochemical yield of 30 percent. The synthesis involved degradation of nonradioactive L'fuconic acid to 5-deoxy-L-lyxose and synthesis from this of $\alpha$-L-fucose$1 .{ }^{14} \mathrm{C}$ by use of ${ }^{14} \mathrm{C}$-labeled cyanide in the cyanohydrin reaction. The resulting epimeric, ${ }^{14} \mathrm{C}$-labeled aldonic acids were separated as either the barium or the sodium salts. Both salts of L-fuconic acid crystallize more readily than the corresponding salts of the epimeric 6-deoxy-L-talonic acid.

The preparation of barium L-fuconate by the electrolytic oxidation of L-fucose in the presence of barium carbonate and barium bromide is described.
\end{abstract}

Key Words: Carbon-14-labeled L -fucose, L-fuconic acid- $l-{ }^{14} C$, L-fucose- $1-{ }^{14} C$, radioactive carbohydrates, synthesis of radioactive sugars.

\section{Introduction}

Polysaccharides containing L-fucose are found in the cell walls of marine algae, in a few gums, and in certain substances of animal origin, such as red bloodcells, blood serum, gastric mucin, ovarian cystofluid, and many other materials of biological importance. Because of the widespread occurrence of L-fucose, the ${ }^{14} \mathrm{C}$-labeled sugar is a valuable research tool. We have carried out the synthesis of $\alpha$-L-fucose- $l-{ }^{14} C$, and have supplied the radioactive sugar to numerous workers engaged in biological research. The method developed for the preparation is outlined below.

The $\alpha$-L-fucose used as the starting material for the separation of the labeled product was obtained from the seaweed Ascophyllum nodosum by a procedure developed earlier, as described in [1]. ${ }^{1}$ The sugar was oxidized electrolytically by the method of Isbell and Frush [2], and the product was separated as crystalline barium L-fuconate. The barium salt was converted into the calcium salt, and this was degraded to 5-deoxy-L-lyxose by the method of Ruff [3] as modified by Hockett and Hudson [4], the proportion of reducing sugar formed from calcium L-fuconate being determined by iodine titration in alkaline solution [5]. In order to ascertain conditions favorable for formation of the fuco (galacto) configuration in the cyanohydrin reaction, test syntheses, beginning with 5-deoxy-L-lyxose, were conducted at the tracer level, and the products were analyzed by the isotopedilution technique $[6,7]$. The results showed that formation of a higher proportion of the fuco configura-

\footnotetext{
${ }^{1}$ Figures in brackets indicate the literature references at the end of this paper.
}

tion is favored by the presence of a general acidcatalyst.

A portion of the crude 5-deoxy-L-lyxose was then treated with sodium cyanide ${ }^{14} C$ in the presence of sodium bicarbonate. The cyanohydrins were carried through the reaction steps shown in figure 1 . The resulting $\alpha$-L-fucose- $I-{ }^{14} C$ crystallized directly from solution (without the intermediate preparation of the phenylhydrazone, a step ordinarily found necessary in the preparation of $\mathrm{L}$-fucose from seaweed). The sodium 6-deoxy-L-talonate- $l-{ }^{14} C$ obtained as a byproduct was retained for future use.

\section{Experimental Details}

\subsection{Barium L-Fuconate [2]}

A mixture of $20.5 \mathrm{~g}$ ( 0.125 mole $)$ of $\alpha$-L-fucose, $4 \mathrm{~g}$ of barium bromide, and $12.5 \mathrm{~g}$ of barium carbonate in $500 \mathrm{ml}$ of water was placed in a 2-liter, 3-necked flask fitted with two graphite electrodes (1 $\mathrm{cm}$ in diameter) and an efficient stirrer. The flask was cooled in ice water, and a direct current of $0.2 \mathrm{~A}$ was passed through the stirred solution. After $34 \mathrm{hr}(6.8 \mathrm{~A}-\mathrm{hr})$, a test for reducing sugar with Benedict reagent [8] was faint, and the electrolysis was stopped. The residual bromine and the barium bromide in the solution were respectively removed by adding $5 \mathrm{~g}$ of a decolorizing carbon and $4.2 \mathrm{~g}$ of silver sulfate. The suspension was filtered, and the residue on the filter was washed with hot water. ${ }^{2}$ The filtrate was treated with hydrogen sulfide to remove residual silver salts, refil-

\footnotetext{
${ }^{2}$ Barium L-fuconate may occasionally crystallize before filtration is conducted. Hence. the precipitate must be thoroughly washed, in order to avoid loss of material.
} 


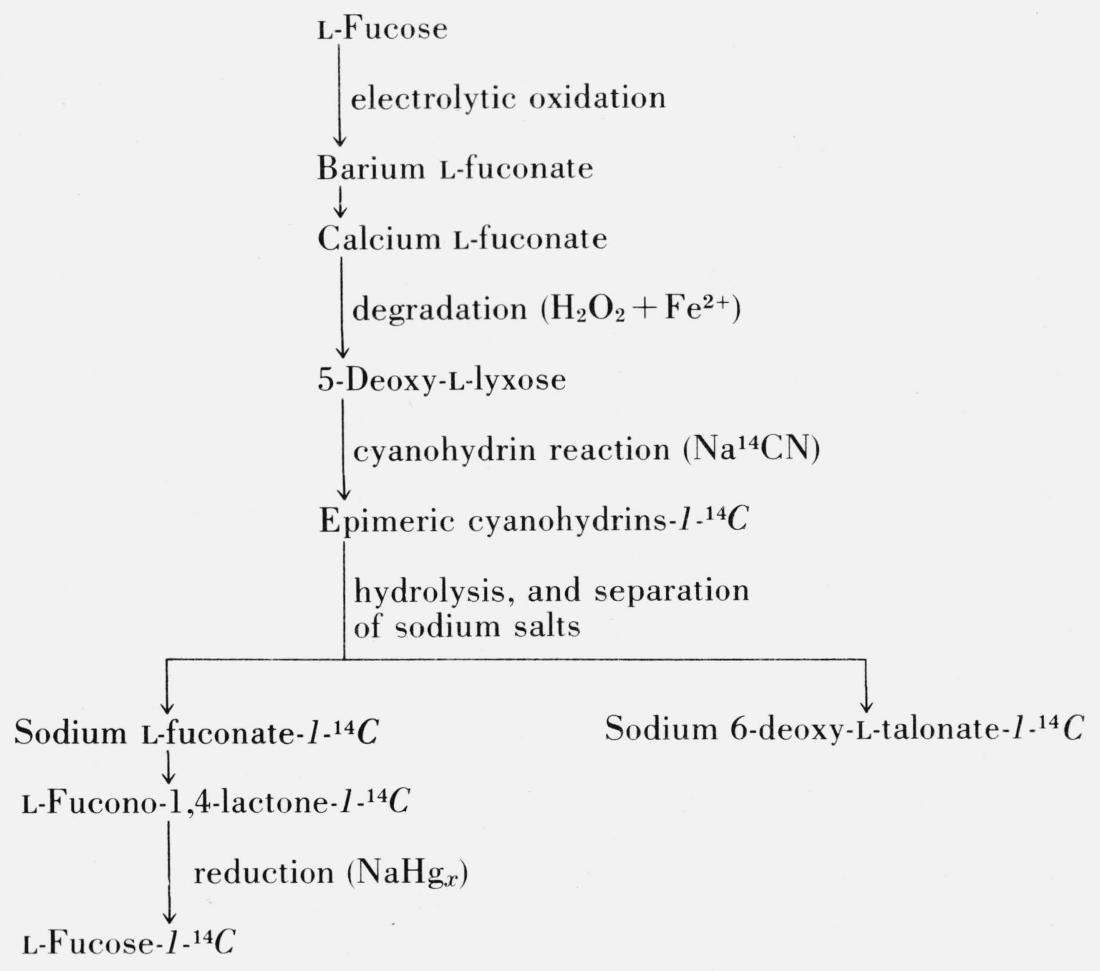

Figure 1. Synthesis of $\alpha-\mathrm{L}-F$ ucose $-1-^{14} \mathrm{C}$.

tered, and concentrated under reduced pressure to a thin syrup, which was diluted with ethyl alcohol to the point of incipient turbidity and nucleated with crystalline barium $\mathrm{L}$-fuconate.

After several hours, a crop of crystals was separated by filtration; by reconcentrating the filtrate and diluting it with ethanol, a second crop was obtained; combined yield, $26 \mathrm{~g}(84 \%)$. The salt, $\mathrm{Ba}\left(\mathrm{C}_{6} \mathrm{H}_{11} \mathrm{O}_{6}\right)_{2}$, was recrystallized from hot water. It was only slightly soluble in water, and showed no optical rotation, in agreement with the reported properties of barium L-fuconate [9]. ${ }^{3}$

\subsection{5-Deoxy-L-lyxose}

Under vigorous stirring, $1.5 \mathrm{~g}$ (3 mmoles) of barium L-fuconate in $50 \mathrm{ml}$ of hot water was successively treated with $6.2 \mathrm{ml}$ of $1 \mathrm{~N}$ sulfuric acid and $350 \mathrm{mg}$ of calcium carbonate. Without removal of the precipitate, the mixture, now containing a solution of calcium L-fuconate, was placed in a water bath at $50{ }^{\circ} \mathrm{C} ; 62$ $\mathrm{mg}$ of barium acetate, $63 \mathrm{mg}$ of ferrous sulfate, and, finally, $0.75 \mathrm{ml}$ of 30 -percent hydrogen peroxide were added, whereupon the mixture turned brown. After $1 \mathrm{hr}$, a second quantity $(0.75 \mathrm{ml})$ of hydrogen peroxide was added. After an additional hour, the suspension was diluted with $25 \mathrm{ml}$ of methyl alcohol and $50 \mathrm{ml}$ of ethyl alcohol, and filtered. The filtrate was concentrated under reduced pressure to about $25 \mathrm{ml}$, and

\footnotetext{
${ }^{3}$ For preparing small quantities of L-fuconic acid, oxidation of L-fucose by bromine [10 or by iodine in alkaline solution [5] is more convenient than the electrolytic method de. scribed here. The resultant bromide or iodide is removed as the silver salt.
}

passed through a column containing $25 \mathrm{ml}$ of mixed (1:1) cation- and anion-exchange resins. The column was well washed with water, and the effluent was concentrated to about $25 \mathrm{ml}$. Titration of an aliquot with iodine in alkaline solution [5] showed the presence of 3.25 mmoles of reducing sugar (54\% of the theoretical yield).

\subsection{Reaction of 5-Deoxy-L-lyxose With Sodium Cyanide}

In order to ascertain favorable conditions for formation of the L-fuconic cyanohydrin from 5-deoxy-Llyxose, the following aqueous reaction mixtures were sealed in glass ampoules and kept for 4 days at about $5{ }^{\circ} \mathrm{C}$.

1. 0.079 mmole of 5-deoxy-L-lyxose in $0.65 \mathrm{ml}$ of solution,

0.07 mmole of sodium cyanide ${ }^{14} C(0.73 \mathrm{mCi} /$ mmole), and

0.30 mmole of sodium hydroxide in $1 \mathrm{ml}$ of solution.

2. 0.079 mmole of 5-deoxy-L-lyxose in $0.65 \mathrm{ml}$ of solution,

$0.05 \mathrm{~g}$ (approximately) of solid carbon dioxide,

0.07 mmole of sodium cyanide ${ }^{14} C(0.73 \mathrm{mCi} /$ mmole), and

0.30 mmole of sodium hydroxide in $1 \mathrm{ml}$ of solution.

In the preparation of the second reaction mixture, the solid carbon dioxide was shaken with the sugar solution and allowed to vaporize before the alkaline 
cyanide solution was added. After 4 days, each ampoule was opened, and the contents were hydrolyzed and treated with cation-exchange resin in a manner similar to that described below for the large preparation. Barium L-fuconate ${ }^{4}(100 \mathrm{mg})$ was added to each solution; after several recrystallizations of the salt, the activities and the corresponding yields of barium $\mathrm{L}$-fuconate- $I-{ }^{14} C$ in the cyanohydrin reaction were as follows: (1) $0.22 \mu \mathrm{Ci} / \mathrm{mg}, 46.5$ percent; (2) $0.28 \mu \mathrm{Ci} / \mathrm{mg}, 60.5$ percent. Hence, the presence of bicarbonate (a general acid-catalyst) favors the formation of the L-fuconic epimer.

\subsection{Sodium L-Fuconate- $l-{ }^{14} C$}

In a 100-ml, round-bottomed flask in an ice-bath, $6 \mathrm{ml}$ of $0.13 M$ 5-deoxy-L-lyxose $(0.78 \mathrm{mmole})$ and 202 $\mathrm{mg}$ of sodium bicarbonate were shaken with a small lump $(0.1 \mathrm{~g})$ of solid carbon dioxide. To this mixture was added $5 \mathrm{ml}$ of a cold solution containing 0.71 mmole $(9.36 \mathrm{mCi})$ of sodium cyanide $-{ }^{14} \mathrm{C}$ and 1.72 mmoles of sodium hydroxide. The mixture was kept in a refrigerator for one day, and at room temperature for four days. Then, $530 \mathrm{mg}$ of sodium carbonate in $10 \mathrm{ml}$ of water was added, and the flask, equipped with an air condenser, was heated in a boiling-water bath until evolution of ammonia had ceased. The solution was stirred with $5 \mathrm{ml}$ of a cation-exchange resin ${ }^{5}$ and passed through a column containing $20 \mathrm{ml}$ of the resin. The effluent (containing $7.74 \mathrm{mCi}$ of activity) was partially concentrated under reduced pressure (to remove carbon dioxide), and neutralized with sodium hydroxide.

Nonradioactive sodium L-fuconate (100 mg) was added, and the solution was concentrated to a syrup which was saturated with methyl alcohol and nucleated. The crystals of sodium L-fuconate- $I-{ }^{14} C$ that formed were separated, and washed with 50 percent aqueous methyl alcohol. The mother liquor was diluted with a solution of $500 \mathrm{mg}$ of nonradioactive sodium L-fuconate and concentrated to a syrup, and the crystals that formed were combined with the first crop and recrystallized; yield, $522 \mathrm{mg}, 4,330 \mu \mathrm{Ci}$. A third crop, obtained by use of nonradioactive carrier, contained $40 \mu \mathrm{Ci}$ of activity. The total yield, $4,370 \mu \mathrm{Ci}$, is 46.7 percent, based on the sodium cyanide ${ }^{14} C$ used.

The mother liquors, containing approximately 3 $\mathrm{mCi}$ of activity, chiefly in the form of sodium 6-deoxyL-talonate, were held for future use.

\subsection{L-Fucono-1,4-lactone- $l-{ }^{14} C$ and Reduction to L-Fucose- $l-{ }^{14} C$}

A solution containing 2.58 mmoles of sodium $\mathrm{L}$ fuconate $-1-{ }^{14} C$ having an activity of $4,330 \mu \mathrm{Ci}$ was passed through a column containing $10 \mathrm{ml}$ of cation-

Although barium L-fuconate was used in the tracer experiments, sodium L-fuconate was later found to have more satisfactory crystallizing properties. Accordingly, the latter salt was used for separation of the epimers in the high-activity preparation reported in the following sections.

5 This caused the evolution of carbon dioxide, and obviated, in part, the formation of gas pockets in the resin column. The column was also back-washed several times during use. Finally, all of the resin was washed until it was substantially free from radioactivity. exchange resin. The effluent was concentrated under reduced pressure, and then divided equally between two reduction tubes described previously [6]. The aqueous solution in each tube was concentrated to a syrup by means of a stream of air introduced through a capillary tube. The acid was lactonized by heating the syrup at $70{ }^{\circ} \mathrm{C}$ with glacial acetic acid. After $1 \mathrm{hr}$ of heating, the completeness of lactonization was tested by paper chromatography and by scanning of the radioactivity in a paper-chromatogram scanner. (Unlactonized acid remains near the origin in the usual developing solvents.) Heating was repeated for an hour, and the tubes were allowed to stand over sodalime in a desiccator for several days. Lactonization appeared to be nearly complete, as shown by test chromatograms.

The lactone (not crystalline) was reduced by the previously described method $[6,11]$, by use of $20 \mathrm{ml}$ of water in each tube, and, per mmole of lactone, $4.6 \mathrm{~g}$ of 5-percent sodium amalgam in the form of pellets [12] and $3.2 \mathrm{~g}$ of sodium hydrogen oxalate. The reduction products in the tubes were combined, and the residual acids were neutralized with sodium hydroxide. Five volumes of methyl alcohol were added, and the mercury and precipitated salts were separated on a filter, washed with methyl alcohol and discarded. The filtrate was concentrated under reduced pressure to about $10 \mathrm{ml}$ and diluted with five volumes of methyl alcohol. The salts that precipitated were removed by filtration, and the filtrate was concentrated to remove the alcohol. The syrup was dissolved in water, and the solution was passed through a column containing $25 \mathrm{ml}$ of a 1:1 mixture of cation- and anionexchange resins.

The effluent (which was shown to be salt-free by testing with a commercial conductivity-meter) was freeze-dried. The residue was dissolved in methyl alcohol, isopropyl alcohol was added to the point of incipient turbidity, and the solution was nucleated. The crystals of $\alpha$-L-fucose- $1{ }^{14} C$ that formed in 24 hr were separated and recrystallized; yield, $113 \mathrm{mg}$ having an activity of $1,168 \mu \mathrm{Ci}$. A second crop, weighing $214 \mathrm{mg}$ after recrystallization, and having an activity of $655 \mu \mathrm{Ci}$, was obtained from the mother liquors by use of $200 \mathrm{mg}$ of nonradioactive L-fucose as the carrier.

When the ion-exchange column was eluted with 10percent aqueous acetic acid, it yielded salts having an activity of $2,057 \mu \mathrm{Ci}$. The effluent was freezedried, and the residue was dissolved in water and passed through a column containing $15 \mathrm{ml}$ of a cationexchange resin. The acid solution was concentrated under reduced pressure, transferred to a reduction tube, lactonized, and reduced with sodium amalgam as described above. After removal of the salts and unreacted L-fuconic acid- $-{ }^{14} C$, the sugar solution was combined with the mother liquor of the first preparation, yielding crystalline $\alpha$-L-fucose $-1-{ }^{14} C$ which, when recrystallized, weighed $288 \mathrm{mg}$ and had an activity of $777 \mu \mathrm{Ci}$.

The elution, lactonization, and reduction procedures were again repeated, and yielded $222 \mathrm{mg}$ of $\alpha$-Lfucose- $1-{ }^{14} C$ having an activity of $222 \mu \mathrm{Ci}$. Thus, the 
total radiochemical yield of $\alpha$-L-fucose- $l-{ }^{14} C$ from sodium L-fuconate- $1-{ }^{14} C$ was $2.8 \mathrm{mCi}$ or 65 percent; the yield of the labeled sugar from sodium cyanide $-{ }^{14} C$ was 30 percent.

\section{References}

[1] F. J. Bates, ed., Polarimetry, saccharimetry and the sugars, NBS Circ. C440 (1942) p. 460.

[2] H. S. Isbell and H. L. Frush, BS J. Res. 6, 1145 (1931) RP328.

[3] O. Ruff, Ber. deut. chem. Ges. 32, 550 (1899); 35, 2360 (1902).

[4] R. C. Hockett and C. S. Hudson, J. Am. Chem. Soc. 56, 1632 (1934).
[5] G. M. Kline and S. F. Acree, BS J. Res. 5, 1063 (1930) RP247; Ind. Eng. Chem., Anal. Ed. 2, 413 (1930).

[6] H. L. Frush and H. S. Isbell, J. Res. NBS 50, 133 (T953) RP2400.

[7] H. L. Frush and H. S. Isbell, J. Res. NBS 5 1, 307 (1953) RP2458.

[8] S. R. Benedict, J. Biol. Chem. 5, 485 (1909).

[9] A. Müther and B. Tollens, Ber. deut. chem. Ges. 37, 306 (1904).

[10] C. S. Hudson and H. S. Isbell, J. Am. Chem. Soc. 51, 2225 (1929).

[11] H. S. Isbell, H. L. Frush, and N. B. Holt, J. Res. NBS 53, 217 (1954) RP2536.

[12] H. S. Isbell, H. L. Frush, and N. B. Holt, J. Res. NBS 64A (Phys. and Chem.) No. 1, 135 (1963).

(Paper 71A2-444) 